Científicas; IUCN Species Survival Commission, Gland, Switzerland; and Provita, Caracas, Venezuela

E-mail jonpaul.rodriguez@gmail.com

\section{Rediscovery of Rhododendron adenosum in south-west China}

Rhododendron adenosum was categorized as Extinct in the Wild both in the Red List of China's Biodiversity-Higher Plants Volume in 2013 and by Qin et al. (2017, Biodiversity Science, 25, 745-757). Other than the specimens collected by Joseph Charles Francis Rock in 1929 (Davidian, 1978, The Quarterly Bulletin of the American Rhododendron Society, 32, 81-85), the species had not been collected in the type location in the Kulu Mountains in Muli county, south-west Sichuan, although four specimens of Rhodode$n$ dron aff. adenosum were collected in 1984 and 2008 in the Luoji Mountains (c. $130 \mathrm{~km}$ from the type location) in Puge county, south-west Sichuan. These four specimens did not, however, have flowers, precluding definitive identification.

With the support of the Second Qinghai-Tibetan Plateau Integrated Scientific Expedition Project (2019QZKKo502), the Biodiversity Survey and Assessment Project of the Ministry of Ecology and Environment of China $\left(2019 \mathrm{HJ}_{2096001006)}\right.$ and the Science and Technology Basic Resources Investigation Program of China (2017FY10010o), field investigations were conducted in May 2020 in both the Luoji Mountains and the type location in the Kulu Mountains. In the Luoji Mountains we confirmed that the specimens of $R$. aff. adenosum were wrongly identified, as they had a campaniform rather than infundibuliform floral shape and a different number of flowers per inflorescence ( $>8$ vs $4-8$ in $R$. adenosum). During 2 days in the Kulu mountains, however, we rediscovered one individual of $R$. adenosum. As there could be additional individuals in the region, we intend to survey the surrounding mountains for the species.

As only one individual $R$. adenosum is currently known it should be categorized as Critically Endangered on the IUCN Red List and as a Plant Species with an Extremely Small Population (Ma et al., 2013, Biodiversity and Conservation, 22, 803-809). In addition to field surveys, propagation experiments will be performed once seeds have been collected in the autumn, and we are discussing with local nature reserves ways to protect the single known individual.

GANG YAO (๑ orcid.org/0000-0002-3628-7088), DetUAN LIU, WeIBANG SUn and YoNGPENG MA Key Laboratory for Plant Diversity and Biogeography of East Asia, Chinese Academy of Sciences, Yunnan Key Laboratory for Integrative Conservation of Plant Species with Extremely Small
Populations, Kunming, Yunnan, China

E-mail mayongpeng@mail.kib.ac.cn

\section{Natural remedies for Covid-19 as a driver of the illegal wildlife trade}

The Covid-19 crisis has highlighted the importance of connections between wildlife and the emergence of novel pandemic diseases in humans (Zhou et al., 2020, Nature, 579, 270-273). The wildlife trade is hypothesized to have played a role in the origins of the current pandemic, resulting in calls for restrictions on the legal wildlife trade, and greater enforcement against the illegal wildlife trade, on public health grounds. There is also speculation about how the pandemic might affect the illegal wildlife trade by making consumption of wildlife products less socially acceptable, or because lockdown measures and travel restrictions may hamper effective regulation of the illegal wildlife trade. Here we highlight a case where Covid-19 is increasing demand for illegal wildlife trade products used as perceived natural disease remedies, drawing on long-term monitoring of the illegal wildlife trade in the northern Caspian Sea.

The illegal wildlife trade in the Caspian region is a significant environmental threat, particularly unregulated illegal fishing targeting the six native Caspian sturgeon species, all of which are Critically Endangered, for their meat and roe (caviar), and for the endemic, Endangered, Caspian seal Pusa caspica. Seals are deliberately targeted and caught as sturgeon fisheries bycatch (Dmitrieva et al., 2013, PLOS ONE, 8, e67074; Ermolin \& Svolkinas, 2018, Marine Policy, $87,284-290$ ). Their pelts are used in the fur trade, and other body parts in traditional medicine. Seal blubber is rendered for oil, which is used as a general health tonic in the Caspian region, as are rendered fats from sturgeons, bears, badgers, wolves and other species (Dmitrieva et al., 2013, op. cit.; L. Svolkinas et al., unpubl. data). Targeting seals and trading in their products is illegal, but compared to other illegal wildlife trade products such as elephant ivory, the trade is not strongly regulated and is not fully clandestine. Fishermen typically sell seal carcasses to middlemen, who render the blubber and wholesale the resulting oil to retailers, with the final product traded openly in regional street marketplaces selling food and household goods.

Our long-term qualitative and quantitative monitoring of marketplaces in the Russian region of Dagestan, in the northern Caspian, shows a trade in seal and sturgeon oil of at least 1,00o 1 per year. Seal oil is considered particularly effective in treating respiratory diseases, including bronchitis, asthma, sinusitis, coughing, colds, pneumonia and tuberculosis. Since the arrival of Covid-19 in the region in March 2020, eight interviews undertaken by LS with key actors in the wildlife oil trade revealed that demand has risen 


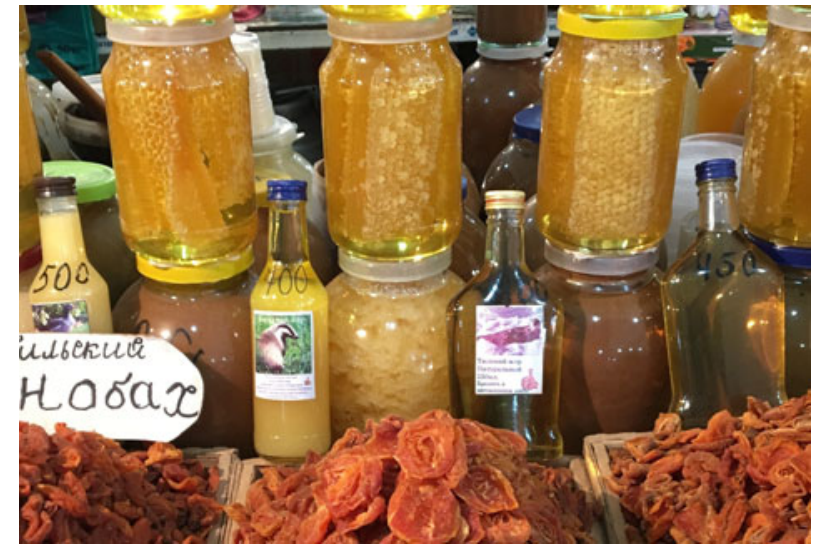

Seal, badger and other types of supposedly medicinal oil traded in marketplaces of the Caspian region, Russian Federation.

to the extent that some traders have exhausted their stock, and consumers are actively seeking new sources of wildlife oil products. This rising demand may put further pressure on threatened Caspian species, given the high Covid-19 incidence in Dagestan.
Wildlife products are used extensively as natural remedies and in traditional medicine around the world. We suggest that monitoring of illegal wildlife trade issues, and discussions of policy responses, should also consider the potential for health pandemics to drive demand for some wildlife products. Solutions should be based on an understanding of trade supply chains, dynamics and underlying causes of consumer demand.

LINAS SVOLKINAS (๑ orcid.org/0000-0003-0925-5846),

SIMON J. GoOdMAN (๑ orcid.org/0000-0003-4118-8575) and

GEORGE HOLMES (๑ orcid.org/0000-0002-5393-5753)

University of Leeds, Leeds, UK

E-mail l.svolkinas@leeds.ac.uk

ILYA ERMOLIN (৫ orcid.org/0000-0002-6490-7715) Plekhanov Russian University of Economics, Moscow, Russian Federation

Pavel SuVorkov (○ orcid.org/0000-0002-9631-3946)

National Research University Higher School of Economics, Moscow, Russian Federation 